\title{
Proposal for a Second Species Within the Genus Ureaplasma, Ureaplasma diversum sp. nov.
}

\author{
C. J. HOWARD AND R. N. GOURLAY \\ A.R.C. Institute for Research on Animal Diseases, Compton, Near Newbury, Berkshire, England
}

\begin{abstract}
It is proposed that a second species should be established within the genus Ureaplasma, Ureaplasma diversum, with strain A417 (NCTC 10182) as the type strain. The new species differs from Ureaplasma urealyticum serologically and on the basis of the guanine-plus-cytosine content of its deoxyribonucleic acid and its protein composition as determined by polyacrylamide gel electrophoresis. The species is serologically heterogeneous, the member strains apparently belonging to one of three serological clusters or groups.
\end{abstract}

The genus Ureaplasma comprises those members of the family Mycoplasmataceae that possess urease activity. There is a single species, Ureaplasma urealyticum, with strain T960 (ATCC 27618) as the type strain (35). In the definition of species within the genera Mycoplasma and Acholeplasma, considerable weight is placed on serological criteria (7). However, $U$. urealyticum was proposed as a serologically heterogeneous species, and in its original description, seven other strains, together with the type strain, were proposed as representatives of serovars (serotypes) I to VIII (35). Comparisons of these serovars by polyacrylamide gel electrophoresis (PAGE) has shown that many polypeptides are shared (34), whereas deoxyribonucleic acid (DNA) homology studies have shown a considerable homology between certain strains representing the serovars (4). These findings have confirmed the original proposal that $U$. urealyticum should be regarded as a single species with several serovars. Certain of these proposed serovars cross-react in some tests, whereas others appear totally distinct $(1,3,6)$. The type strain of $U$. urealyticum and the strains of the other seven serovars were isolated from humans. Other isolates have been made from humans that are probably further serovars of the same species $(26,31)$.

Ureaplasmas have been isolated from a number of animal species other than humans. These include cattle, dogs, cats, and nonhuman primates (39), sheep (27), birds (36), pigs (37), and mink (8). Of these, the bovine isolates have probably been the most studied, and the question has been raised as to whether isolates from cattle should be classified as $U$. urealyticum or whether they are sufficiently distinct to form a separate species. Clearly, since $U$. urealyticum is serologically heterogeneous, serological dif- ferences between that species and bovine isolates alone are insufficient to propose a separate species. However, evidence has been accumulated indicating that certain bovine isolates are distinct from $U$. urealyticum not only serologically but also on the basis of the guanine-pluscytosine $(\mathrm{G}+\mathrm{C})$ contents of their DNAs and their polypeptides, as compared by PAGE.

This paper outlines the basic characteristics of ureaplasmas from cattle and defines their unique biological and serological properties. We hereby propose a second species within the genus Ureaplasma, with strain A417 (NCTC 10182) as the type strain.

\section{MATERIALS AND METHODS}

Media. Unless stated otherwise, isolates were grown in U4 broth or on U4 solid medium (19). The solid medium was modified slightly and contained $0.01 \%$ urea. Broth cultures were incubated aerobically at $37^{\circ} \mathrm{C}$, whereas solid medium was incubated at $37^{\circ} \mathrm{C}$ under an atmosphere of $100 \% \mathrm{CO}_{2}$.

Strains. $U$. urealyticum strains $7,23,27,58,354, \mathrm{Pi}$, $\mathrm{Co}$, and T960, serovars I to VIII (35), were obtained from F. T. Black, Aarhus, Denmark. The sources of bovine strains A417, Bu2, Mmb167, T95, T288, T45, $\mathrm{D} 48, \mathrm{~T} 315, \mathrm{~T} 44, \mathrm{~T} 71$, and $\mathrm{T} 74$, considered to be representative of the serological diversity of bovine isolates, have been previously described (19); strain A417 originated from a pneumonic calf lung. All of these strains were cloned by filtering broth cultures (450-nm Millipore membrane) and picking single colonies at least four times.

Stock broth cultures of cloned strains were stored at $-70^{\circ} \mathrm{C}$ and subcultured as required.

Morphology. Morphology was examined by using cells collected by centrifugation $(10,000 \times g$ for 30 $\mathrm{min})$. Drops of suspensions on glass slides were air dried, fixed in methanol, stained with Gram or Giemsa stain, and examined by light microscopy.

For examination by electron microscopy (Phillips EM300; accelerating voltage of $80 \mathrm{kV}$ ), pelleted organisms were fixed with phosphate-buffered glutaralde- 
hyde and stained with uranyl acetate and lead citrate (15).

Filtration studies. Numbers of color-changing units (CCU) in overnight cultures were determined in triplicate before and after passage of separate portions through membrane filters of $650-, 450-, 220-$, and 100$\mathrm{nm}$ average pore diameters (Millipore) at a positive pressure of 5 to $10 \mathrm{lb} / \mathrm{in}^{2}\left(34.4\right.$ to $\left.68.8 \mathrm{kN} / \mathrm{m}^{2}\right)$.

PAGE. Details of the method used to examine $\left[{ }^{35} \mathrm{~S}\right]$ methionine-labeled polypeptides from ureaplasma strains by sodium dodecyl sulfate-PAGE have been published (23).

Biochemical tests. The ability to catabolize urea or arginine was examined in broth cultures by inoculating isolates into $\mathrm{U} 4$ broth containing $0.05 \%$ urea, $\mathrm{U} 4$ broth with urea omitted and containing $0.5 \%$ arginine, or U4 broth with urea omitted and with no added arginine. The inoculated broths and uninoculated controls were incubated at $37^{\circ} \mathrm{C}$ and examined over 14 days for an alkaline color change indicating catabolism of either compound.

The ability to hydrolyze urea was also tested by a method similar to that of Swanberg et al. (38). Briefly, $\left[{ }^{14} \mathrm{C}\right]$ urea $(57 \mu \mathrm{Ci} / \mu \mathrm{mol}$; Amersham, Great Britain) was added to $\mathrm{U} 4$ broth to give a final concentration of $1.25 \mu \mathrm{Ci} / \mathrm{ml}$. Pentuplicate inoculated broths and uninoculated controls were incubated at $37^{\circ} \mathrm{C}$ for $48 \mathrm{~h}, 0.1$ $\mathrm{ml}$ of $3 \mathrm{~N} \mathrm{H}_{2} \mathrm{SO}_{4}$ was added per $\mathrm{ml}$ of broth, and the broths were incubated in a fume hood at room temperature for $2 \mathrm{~h}$, with occasional shaking, to remove $\mathrm{CO}_{2}(28)$. Samples $(100 \mu \mathrm{l}$ each) were mixed with $3 \mathrm{ml}$ of scintillation fluid (KL402; Koch-Light Laboratories Ltd.), the radioactivity was counted in a Packard 2425 scintillation counter, and the percentage of urea catabolized was calculated.

Sterol requirement. The requirement for sterol was determined by a broth culture method similar to that described by Razin and Tully (30). Basal broth was prepared containing $70 \mathrm{ml}$ of PPLO broth (Difco Laboratories, Detroit, Mich.), $10 \mathrm{ml}$ of yeast extract ( $25 \%$ [wt/vol] $), 0.25 \mathrm{ml}$ of phenol red ( $1 \%$ [wt/vol]), 0.5 $\mathrm{ml}$ of thallium acetate (5\% [wt/vol]), $0.5 \mathrm{ml}$ of ampicillin (Beechams; $20 \%$ [wt/vol]), and $0.25 \mathrm{ml}$ of urea $(20 \%$ [wt/vol]). The following supplements were then added to give the indicated final concentrations: (i) fetal calf serum $(20 \%$ [vol/vol]), (ii) bovine serum albumin (Armour fraction $\mathrm{V} ; 0.5 \%)$ plus palmitic acid $(10 \mu \mathrm{g} / \mathrm{ml})$ together with either PPLO serum fraction (Difco; $1 \%$ [vol/vol]) or cholesterol at one of three concentrations $(100,25$, or $5 \mu \mathrm{g} / \mathrm{ml})$, (iii) bovine serum albumin plus palmitic acid without any cholesterol-containing supplement, and (iv) no added supplements. The volume was made up with water. Broths were inoculated with a washed suspension of ureaplasmas in $0.15 \mathrm{M}$ phosphate-buffered saline ( $\mathrm{pH} 7.2$ ) containing $10^{2}$ or $10^{3}$ $\mathrm{CCU} / \mathrm{ml}$ and examined daily for growth, indicated by an alkaline color change in the medium.

A requirement for sterol was also determined in the indirect way by determining whether growth on agar was inhibited by disks containing $1.5 \%(\mathrm{wt} / \mathrm{vol})$ digitonin.

Serological tests. The metabolism inhibition (MI) test (14), growth inhibition (GI) test (19), and indirect immunofluorescent antibody (IF) test (18) were used with rabbit antisera. The IF test was used with antisera raised in gnotobiotic calves (16).

\section{RESULTS}

Morphology and growth characteristics. Smears from broth cultures of strain A417 stained by the Gram technique revealed gramnegative organisms. After Giemsa staining, pleomorphic but essentially round or coccobacillary bodies were seen, with a few larger ring forms visible. Electron microscopic examination of thin sections of cell pellets stained with uranyl acetate showed pleomorphic organisms with a unit membrane and no evidence of a cell wall outside the membrane (Fig. 1). Colonies on solid medium containing $20 \%$ ( $\mathrm{vol} / \mathrm{vol}$ ) horse serum showed a typical fried egg morphology (Fig. 2). U4 broth inoculated with $10^{3} \mathrm{CCU}$ produced an alkaline color change after $24 \mathrm{~h}$ of incubation at $37^{\circ} \mathrm{C}$ and contained $10^{6}$ to $10^{7} \mathrm{CCU} / \mathrm{ml}$.

The $\mathrm{pH}$ for optimum growth was determined by inoculating $10^{2}$ or $10^{3} \mathrm{CCU}$ of strain $\mathrm{A} 417$ into $\mathrm{U} 4$ broth with the $\mathrm{pH}$ adjusted to values varying by $0.5 \mathrm{pH}$ units over the range 4.0 to 8.0 . Growth, as indicated by a color change in the broths, was observed within 1 day in broths at pH 6.0, 6.5, and 7.0. Subsequently, growth was also observed in broth ranging from $\mathrm{pH} 5.5$ to 7.5. No growth was apparent in broths at $\mathrm{pH} 4.0$ to 5.0 or at $\mathrm{pH} 8.0$. Thus, optimum growth appeared to occur in the $\mathrm{pH}$ range of 6.0 to 7.0. Similar results were obtained with two other strains, D48 and T44.

$\mathrm{U} 4$ broth was inoculated with $10^{2}$ or $10^{3} \mathrm{CCU}$ of strain A417 and incubated at 18, 25, 28, 32, 35, 37 , and $42^{\circ} \mathrm{C}$. Growth, as indicated by a color change, was observed in broths incubated at 33 , 35 , and $37^{\circ} \mathrm{C}$ but not in broths incubated at the other temperatures. Similar results were observed with strains D48 and T44.

Reversion studies. Strain A417 passaged seven times, to a level representing a dilution of $10^{-21}$, in broth from which bacterial inhibitors had been omitted showed no reversion to bacterial forms when examined by Giemsa stain or when cultured on ox blood agar. No difference in colony morphology, size, or numbers was observed when growth on complete U4 solid medium was compared to that on $\mathrm{U} 4$ medium from which penicillin and thallium acetate had been omitted.

Filtration studies. A culture of strain A417 contained $10^{4.8} \mathrm{CCU} / \mathrm{ml}$ before filtration through membrane filters. The number of $\mathrm{CCU}$ per milliliter after filtration through filters of 650- , 450- , $220-$, and $100-\mu \mathrm{m}$ average pore size were $10^{4.5}$, $10^{3.5}, 10^{1.5}$, and $<10^{1}$, respectively. The cloning of strains selected for use as antigens for antiserum production involved filtration through 450nm Millipore membranes; thus, these strains were all capable of passing through membranes with this pore size.

Sterol requirements. In the disk inhibition test 


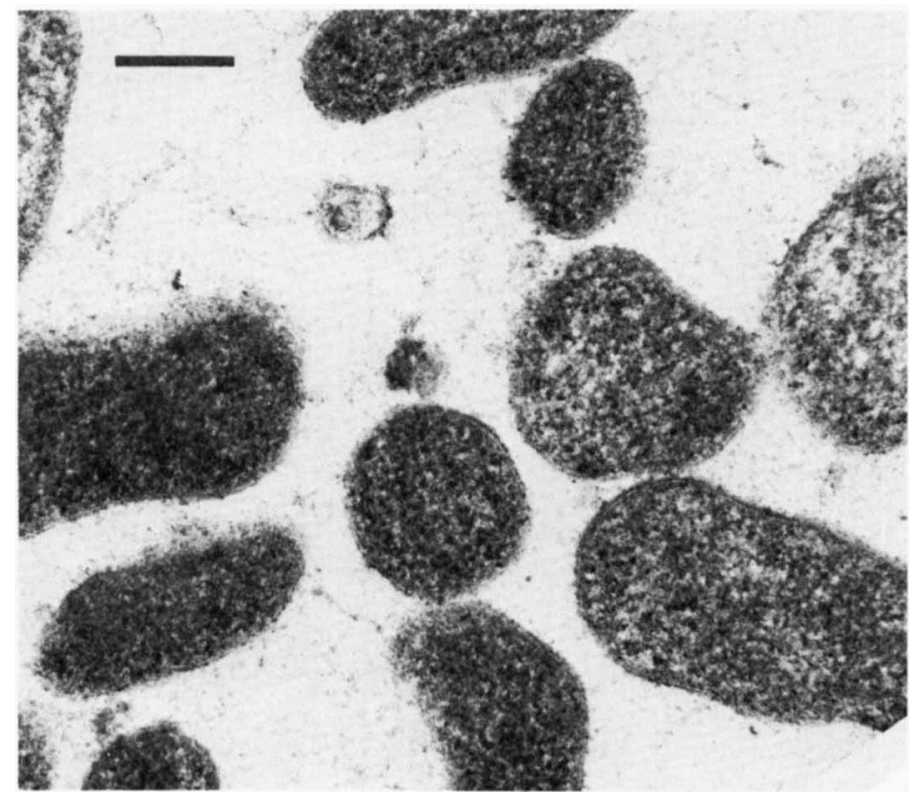

FIG. 1. Electron micrograph of thin section of strain A417 stained with uranyl acetate. Bar, $200 \mathrm{~nm}$.

on solid medium, zones of inhibition of growth of strain A417 extended $7 \mathrm{~mm}$ from disks containing digitonin. No inhibition of growth was observed around disks not containing the compound. Similar results were observed with strains D48 and T44.

Strain A417 failed to grow in broth from which serum was omitted (basal broth). Furthermore, no growth was observed when bovine serum albumin and palmitic acid were added to the basal broth. Growth did occur in basal broth containing bovine serum albumin and palmitic acid plus PPLO serum fraction or cholesterol (at all three concentrations) and in basal broth containing serum.

Biochemical characteristics. Strain A417 produced a slight alkaline color change associated with a $\mathrm{pH}$ rise from $\mathrm{pH} 6.2$ to $\mathrm{pH} 6.7$ in $\mathrm{U} 4$ broth with urea omitted. In media made to the same formulation but containing $0.05 \%$ urea, a rise from $\mathrm{pH} 6.2$ to 7.8 was produced, indicating that urea was catabolized. In broth not containing added urea but containing $0.5 \%$ arginine, the rise in $\mathrm{pH}$ after inoculation of strain $\mathrm{A} 417$ was similar to that in broth from which urea and arginine had been omitted. Thus, no evidence was seen for arginine catabolism.

In broth containing $\left[{ }^{14} \mathrm{C}\right]$ urea and inoculated with strain $\mathrm{A} 417,<35 \%$ of the $\left[{ }^{14} \mathrm{C}\right]$ urea remained after incubation, compared with $100 \%$ in similarly incubated but uninoculated broths. This confirmed the presence of urease activity.

Polyacrylamide gel patterns. A comparison by PAGE of polypeptides from strains T960 and
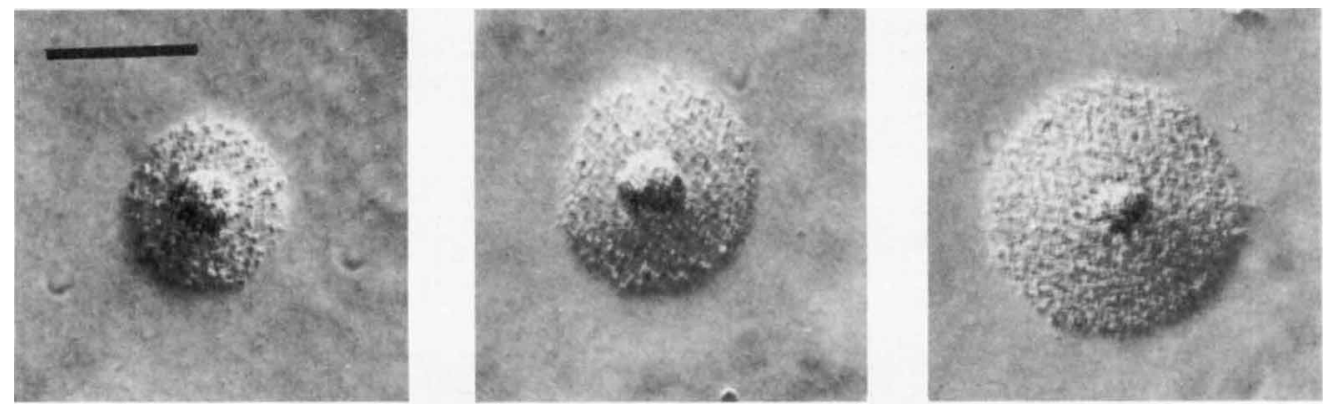

FIG. 2. Appearance of strain A417 on solid medium containing $10 \%$ (vol/vol) horse serum. The culture was incubated for 5 days at $37^{\circ} \mathrm{C}$ under $100 \% \mathrm{CO}_{2}$. Bar, $100 \mu \mathrm{m}$. 


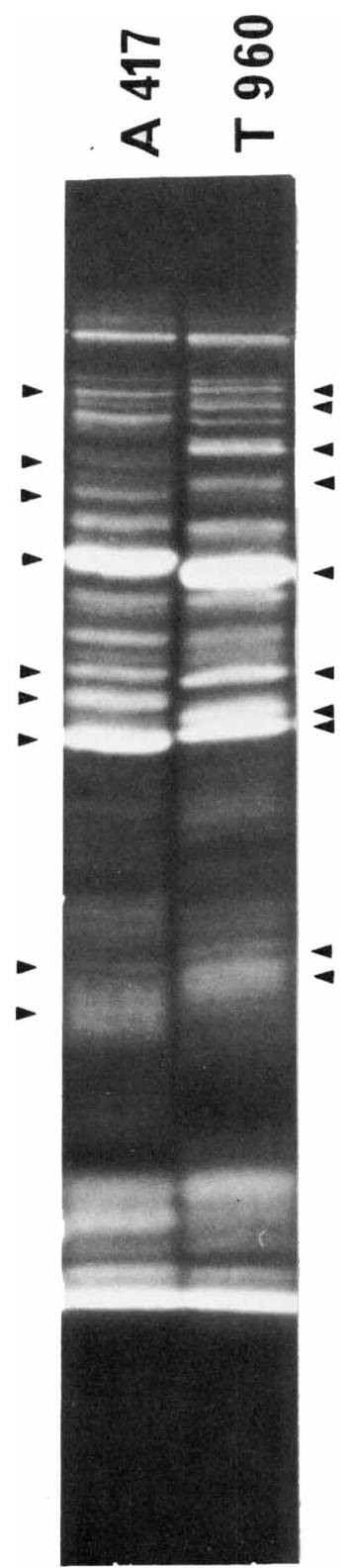

FIG. 3. Analysis of whole cell lysates of ureaplasma strains A417 and T960, grown in the presence of $\left[{ }^{35} \mathrm{~S}\right]$ methionine, by sodium dodecyl sulfate-PAGE. Numbers across the top indicate strains. The two samples were run on the same gel. Arrows indicate dissimilar polypeptides.

A417 labeled by growth in the presence of ${ }^{35}$ S]methionine showed the two strains to be distinct (Fig. 3).

Previous studies had shown that serovars I to VII of $U$. urealyticum had many polypeptides common to strain T960, that representative bo- vine ureaplasmas had many polypeptides common to strain A417, and that the bovine isolates appeared distinct from the human ones (23).

DNA base composition. The $\mathrm{G}+\mathrm{C}$ content of the DNA from strain A417 has been found to be $29.0 \mathrm{~mol} \%$. The range of values for 10 bovine isolates has been found to be from 28.7 to 30.2 mol\% $(20,22)$.

Serological studies. Comparisons of bovine ureaplasmas by MI, GI, and IF tests with rabbit antisera indicated that three clusters of serologically similar, but not identical, strains existed $(14,18,29)$. Three strains, A417, D48, and T44, were selected as representatives of these three clusters, and it appears that bovine ureaplasmas can be identified by antisera raised in gnotobiotic calves to just three strains (16).

No serological relationship has been found between strain $\mathrm{A} 417$ and $U$. urealyticum strain T960 by the GI or IF tests with rabbit or calf antisera $(14,16,18,19,29)$. Also, no relationship has been found between strain A417, or any other representative bovine ureaplasma isolate, and the eight serovars of $U$. urealyticum by these tests. A small, insignificant level of crossreaction has been seen in the MI test between some bovine and human isolates $(14,41)$.

Habitat. Ureaplasmas representing one or more of the three serological clusters have been isolated from apparently normal and from diseased urogenital tracts from male and female cattle $(33,40,42)$, from the eyes of cattle with keratoconjunctivitis (13), and from pneumonic calf lungs (10). The host range in other animals has not been determined.

Pathogenicity. Under controlled experimental conditions, strain A417 has been reported to produce mastitis in cows (12) and pneumonia in gnotobiotic calves (21). Other reports indicate that bovine ureaplasmas produce vulvitis (5) and conjunctivitis (32) experimentally in cattle. As inferred from ability or inability to produce mastitis experimentally, both virulent and avirulent strains exist in the cattle population (17). Thus, bovine ureaplasmas are potential pathogens.

Strain A417 has been shown to produce mastitis experimentally in goats (11); however, the relation between ovine and caprine ureaplasmas and bovine isolates remains to be elucidated. Ovine and caprine strains have been found to have $\mathrm{G}+\mathrm{C}$ contents similar to, but perhaps marginally higher than, those of bovine isolates (22) but have been reported to be serologically distinct from bovine strains (25).

\section{DISCUSSION}

The results presented here indicate that strain A417 should be classified in the genus Urea- 
plasma, but that this strain and other similar isolates from cattle are sufficiently distinct from the type strain of $U$. urealyticum and other similar human isolates to be regarded as a second species within the genus Ureaplasma.

The morphology of cells of strain A417 and the form of the colony, the absence of a cell wall, the resistance to penicillin and thallium acetate, the inability to grow at $25^{\circ} \mathrm{C}$, the susceptibility to digitonin, the requirement for cholesterol, and the ability to pass through membrane filters indicate that strain A417 should be classified in the family Mycoplasmataceae (7). The possession of urease activity, the occurrence of optimum growth at $\mathrm{pH} 6.0$ to 7.0 , and the relatively small colony size indicate that this isolate should be classified in the genus Ureaplasma (35).

Since $U$. urealyticum is considered to be a species comprised of several serovars, it is clear that serological difference alone is not sufficient for proposing new isolates, from whatever source, as separate species. Nevertheless, it would seem to be necessary to show that a proposed second species was serologically distinct from the named species $U$. urealyticum. Strain T960, the type strain of $U$. urealyticum, is a member of serovar VIII. Other strains representing serovars I to VII were described at the same time as the type strain (35). Some crossreactions occur between certain of the strains proposed as representative of serovars $(1,3,6)$, and other strains have been isolated from humans that probably represent further serovars $(26,31)$.

Bovine ureaplasmas appear to exist as three serological clusters defined by rabbit antisera $(18,29)$ and as three serovars defined by gnotobiotic calf sera (16). The three clusters defined by rabbit antisera and the serovars defined by calf sera coincide.

Strain A417 is distinct from strain T960 and from members of other $U$. urealyticum serovars by a variety of serological tests, including MI, GI, and IF. In fact, no significant cross-reactions have been demonstrated among the eight $U$. urealyticum serovars and representative bovine isolates $(16,19,29)$.

The $\mathrm{G}+\mathrm{C}$ content of the DNA from $U$. urealyticum strain T960 was reported to be $27.1 \mathrm{~mol} \%$ by Black et al. (2). Subsequently, the G+C content of strain A417 was reported to be 29.0 mol\%. In the latter study, strain T960, which was included to make comparisons possible, was reported to have a $\mathrm{G}+\mathrm{C}$ content of 27.4 $\mathrm{mol} \%$ (20), a value virtually the same as that published previously. Although strains T960 and A417 have $\mathrm{G}+\mathrm{C}$ contents that are different, the difference is not great. However, the range of values for eight $U$. urealyticum strains is 26.9 to
$28.0 \mathrm{~mol} \%$ (2), and this does not overlap the range ( 28.7 to $30.2 \mathrm{~mol} \%$ ) found for 10 bovine isolates $(20,22)$. These findings indicate that bovine isolates are a population distinct from those isolates classified as $U$. urealyticum.

Furthermore, the polypeptides of strains T960 and A417 are distinct when compared by PAGE. This method is considered to be suitable for distinguishing microorganisms at the level of species $(7,24)$. Other human isolates have been shown to have many polypeptides in common with strain T960, whereas other bovine isolates examined have many polypeptides in common with strain A417 but not with the human isolates $(23,34)$. Although some bovine isolates are distinct from strain A417 on the basis of serology, their polypeptides appear similar, and the bovine ureaplasmas are probably best regarded as belonging to one of three groups of the same species.

Thus, it is proposed that strain A417, which has been deposited in the National Collection of Type Cultures, London, England, as NCTC 10182 , should be the type strain of the new species Ureaplasma diversum sp. nov. (L. adj. diversus different, distinct, heterogeneous; referring to the difference in polypeptides and $\mathrm{G}+\mathrm{C}$ content, compared to $U$. urealyticum, and to the heterogeneous antigenic structure of the species).

As necessary (9), the proposal made here reflects the properties inherent in the strain and not the source of isolation; typically, however, $U$. urealyticum is not isolated from cattle and $U$. diversum is not isolated from humans.

As a consequence of these proposals, it would seem logical to compare isolates from other animal species with the representative $U$. urealyticum and $U$. diversum strains; as a minimum, antigenic structure, $\mathrm{G}+\mathrm{C}$ content of the DNA, and the polypeptides should be examined. Although some strains are probably sufficiently similar to the two named species to be classified with them, some are almost certain to be sufficiently distinct to be regarded as further species.

\section{ADDENDUM}

Since this manuscript was submitted, a study has been reported (C. Mouches, D. Taylor-Robinson, L. Stipkovits, and J. M. Bøve, Ann. Inst. Pasteur Paris 132B:171-196, 1981) which has confirmed by twodimensional PAGE that bovine strains are distinct from those from humans and that they appear to fall into three groups coinciding with antigenic structure.

\section{ACKNOWLEDGMENTS}

We thank P. Bland for the electron micrograph, I. Jebbett for the photographs, and D. H. Pocock for his collaboration on the PAGE determinations.

\section{REPRINT REQUESTS}

Address reprint requests to: Dr. C. J. Howard, A. R. C. 
Institute for Research on Animal Diseases. Compton, $\mathrm{Nr}$ Newbury, Berkshire RG16 ONN. England.

\section{LITERATURE CITED}

1. Black, F. T. 1973. Modifications of the growth inhibition test and its application to human T-mycoplasmas. Appl. Microbiol. 25:528-533.

2. Black, F. T., C. Christiansen, and G. Askaa. 1972. Genome size and base composition of deoxyribonucleic acid from eight human T-mycoplasmas. Int. J. Syst. Bacteriol. 22:241-242.

3. Black, F. T., and A. Krogsgaard-Jensen. 1974. Application of indirect immunofluorescence, indirect haemagglutination and polyacrylamide-gel electrophoresis to human $\mathrm{T}$ mycoplasmas. Acta. Pathol. Microbiol. Scand. Sect. B 82:345-353.

4. Christiansen, C., E. A. Freundt, and F. T. Black. 1981 Hybridization experiments with DNA from Ureaplasma urealyticum. serotypes I to VIII. Int. J. Syst. Bacteriol. 31:259-262

5. Doig. P. A., H. L. Ruhnke, and N. C. Palmer. 1980 Experimental bovine genital ureaplasmosis. 1. Granular vulvitis following vulvar inoculation. Can. J. Comp. Med. 44:252-258.

6. Ford, D. K. 1967. Relationships between mycoplasma and the etiology of nongonococcal urethritis and Reiter's syndrome. Ann. N.Y. Acad. Sci. 143:501-504.

7. Freundt, E. A., and D. G. ff. Edward. 1979. Classification and taxonomy, p. 1-41. In M. F. Barile and S. Razin (ed.), The mycoplasmas, vol. 1. Academic Press, Inc., New York.

8. Friis, N. F., K. B. Pedersen, and B. Bloch. 1980. Ureaplasma isolated from the respiratory tract of mink. Acta Vet. Scand. 21:134-136.

9. Gordon, R. E. 1978. A species definition. Int. J. Syst. Bacteriol. 28:605-607.

10. Gourlay, R. N. 1968. The isolation of T-strains of mycoplasma from pneumonic calf lungs. Res. Vet. Sci. 9:376378 .

11. Gourlay, R. N., J. Brownlie, and C. J. Howard. 1973. Isolation of $\mathrm{T}$-mycoplasmas from goats, and the production of subclinical mastitis in goats by the intramammary inoculation of human T-mycoplasmas. J. Gen. Microbiol. 76:251-254.

12. Gourlay, R. N., C. J. Howard, and J. Brownlie. 1972. The production of mastitis in cows by the intramammary inoculation of T-mycoplasmas. J. Hyg. 70:511-521.

13. Gourlay, R. N. and L. H. Thomas. 1969. The isolation of large colony and T-strain mycoplasmas from cases of bovine kerato-conjunctivitis. Vet. Res, 84:416-417.

14. Howard, C. J., and R. N. Gourlay. 1973. Serological comparison of bovine T-mycoplasmas. J. Gen. Microbiol. 79:129-134.

15. Howard, C. J., and R. N. Gourlay. 1974. An electronmicroscopic examination of certain bovine mycoplasmas stained with ruthenium red and the demonstration of a capsule on Mycoplasma dispar. J. Gen. Microbiol. 83:393-398.

16. Howard, C. J., and R. N. Gourlay. 1981. Identification of ureaplasmas from cattle using antisera prepared in gnotobiotic calves. J. Gen. Microbiol. 126:365-369.

17. Howard, C. J., R. N. Gourlay, and J. Brownlie. 1973. The virulence of $\mathrm{T}$-mycoplasmas, isolated from various animal species, assayed by intramammary inoculation in cattle. J. Hyg. 71:163-170.

18. Howard, C. J., R. N. Gourlay, and J. Collins. 1975. Serological comparison between twenty-five bovine Ureaplasma (T-mycoplasma) strains by immunofluorescence. Int. J. Syst. Bacteriol. 25:155-159.

19. Howard, C. J., R. N. Gourlay, and J. Collins. 1978. Serological studies with bovine ureaplasmas (T-mycoplasmas). Int. J. Syst. Bacteriol. 28:473-477.

20. Howard, C. J., R. N. Gourlay, D. J. Garwes, D. H. Pocock, and J. Collins. 1974. Base composition of deoxyribo- nucleic acid from bovine T-mycoplasmas. Int. J. Syst. Bacteriol. 24:373-374.

21. Howard, C. J., R. N. Gourlay, L. H. Thomas, and E. J. Stott. 1976. Induction of pneumonia in gnotobiotic calves following inoculation of Mycoplasma dispar and ureaplasmas (T-mycoplasmas). Res. Vet. Sci. 21:227-231.

22. Howard, C. J., D. H. Pocock, and R. N. Gourlay. 1978. Base composition of deoxyribonucleic acid from ureaplasmas isolated from various animal species. Int. J. Syst. Bacteriol. 28:599-601.

23. Howard, C. J., D. H. Pocock, and R. N. Gourlay. 1981. Polyacrylamide gel electrophoretic comparison of the polypeptides from ureaplasmas isolated from cattle and humans. Int. J. Syst. Bacteriol. 31:128-130.

24. Kersters, K., and J. De Ley. 1980. Classification and identification of bacteria by electrophoresis of their proteins, p. 273-297. In M. Goodfellow and R. G. Board (ed.), Microbiological classification and identification. Soc. Appl. Microbiol. Symp. Ser. 8. Academic Press, Inc., New York.

25. Kotani, H., H. Nagatomo, and M. Ogata. 1980. Isolation and serological comparison of ureaplasmas from goats and sheep. Jpn. J. Vet. Sci. 42:31-40.

26. Lin, J.-S. L., M. I. Kendrick, and E. H. Kass. 1972. Serologic typing of human genital T-mycoplasmas by a complement-dependent mycoplasmacidal test. J. Infect. Dis. 126:658-663.

27. Livingston, C. W., and B. B. Gauer. 1975. Isolation of Tstrain mycoplasma from sheep and goats in Texas. Am. J. Vet. Res. 36:313-314.

28. Masover, G. K., J. E. Sawyer, and L. Hayflick. 1976. Urea-hydrolysing activity of a T-strain mycoplasma: Ureaplasma urealvicum. J. Bacteriol. 125:581-587.

29. Ogata, M., H. Kotani, and K. Yamamoto. 1979. Serological comparison of bovine ureaplasmas. Jpn. J. Vet. Sci. 41:629-637

30. Razin, S., and J. G. Tully. 1970. Cholesterol requirement of mycoplasmas. J. Bacteriol. 102:306-310.

31. Robertson, J. A., and G. W. Stemke. 1979. Modified metabolic inhibition test for serotyping strains of Ureaplasma urealyticum (T-strain mycoplasma). J. Clin. Microbiol. 9:673-676.

32. Rosenbusch, R. F., and W. U. Knudtson. 1980. Bovine mycoplasmal conjunctivitis: experimental reproduction and characterization of the disease. Cornell Vet. 70:307320 .

33. Ruhnke, H. L., P. A. Doig, A. L. MacKay, A. Gagnon, and M. Kierstead. 1978. Isolation of ureaplasma from bovine granular vulvitis. Can. J. Comp. Med. 42:151-155.

34. Sayed, I. A., and G. E. Kenny. 1980. Comparison of the proteins and polypeptides of the eight serotypes of Ureaplasma urealyticum by isoelectric focusing and sodium dodecyl sulfate-polyacrylamide gel electrophoresis. Int. J. Syst. Bacteriol. 30:33-41.

35. Shepard, M. C., C. D. Lunceford, D. K. Ford, R. H. Purcell, D. Taylor-Robinson, S. Razin, and F. T. Black. 1974. Ureaplasma urealyticum gen. nov., sp. nov.: proposed nomenclature for the human $\mathrm{T}$ ( T-strain) mycoplasmas. Int. J. Syst. Bacteriol. 24:160-171.

36. Stipkovits, L., and A. Rashwan. 1976. Isolation of ureaplasmas from chickens. Proc. Soc. Gen. Microbiol. 3:158.

37. Stipkovits, L., A. Rashwan, J. Takacs, and K. Lapis. 1978. Occurrence of ureaplasmas in swine semen. Zentralbl. Veterinaermed. Reihe B 25:605-608.

38. Swanberg, S. L., G. K. Masover, and L. Hayflick. 1978. Some characteristics of Ureaplasma urealyticum and urease activity in a simple buffer: effect of metal ions and sulphydryl inhibitors. J. Gen. Microbiol. 108:221-225.

39. Taylor-Robinson, D., and P. Furr. 1973. The distribution of T-mycoplasmas within and among various animal species. Ann. N.Y. Acad. Sci. 225:108-117.

40. Taylor-Robinson, D., D. Haig, and M. H. Williams. 1967. Bovine T-strain mycoplasma. Ann. N.Y. Acad. Sci. 143:517-518. 
41. Taylor-Robinson, D., C. Martin-Bourgon, T. Watanabe, and J. P. Addey. 1971. Isolation of T-mycoplasmas from dogs and squirrel monkeys: biological and serological comparison with those isolated from man and cattle. J.
Gen. Microbiol. 68:97-107.

42. Taylor-Robinson, D., M. Thomas, and P. L. Dawson. 1969. The isolation of T-mycoplasmas from the urogenital tract of bulls. J. Med. Microbiol. 2:527-533. 